\title{
EFFECTS OF INTRA- AND INTER-SPECIFIC SOCIAL STIMULATION ON IMPLANTATION IN DEERMICE
}

\author{
F. H. BRONSON, B. E. ELEFTHERIOU* AND E. I. GARICK \\ The Fackson Laboratory, Bar Harbor, Maine, U.S.A. \\ (Received 16th September 1963, revised 30th January 1964)
}

\begin{abstract}
Summary. Inseminated deermice (Peromyscus maniculatus bairdii) were exposed for $24 \mathrm{hr}$ to strange male or female (1) P. m. bairdii; (2) P. m. gracilis (an inter-fertile subspecies); or (3) C57BL/10J house mice (members of a different family of rodents). Implantation was significantly affected except in the case of exposure to bairdii or C57BL/10J females. Exposure to male bairdii and male gracilis caused the highest incidence of blocked pregnancies. Differences between the sexes in producing implantation failures in inseminated bairdii were marked in bairdii and negligible in gracilis and $\mathrm{C} 57 \mathrm{BL} / 10 \mathrm{~J}$ mice.
\end{abstract}

\section{INTRODUCTION}

Bruce $(1959,1960)$, working with laboratory mice, described an exteroceptive, pre-implantation block to pregnancy, evoked by the presence of strange males. Parkes \& Bruce (1961), in their review of this phenomenon, concluded: (1) pregnancy is blocked by the odour of a strange male; (2) the effect is enhanced if the strange male is of a different strain from that of the stud male; (3) the block is characterized by a return to oestrus, i.e. both pregnancy and pseudopregnancy are blocked; they suggested that the phenomenon might involve a failure of normal luteotrophin production. Testing for the generality of this phenomenon, Eleftheriou, Bronson \& Zarrow (1962) and Bronson \& Eleftheriou (1963) reported that exposure of inseminated prairie deermice (Peromyscus maniculatus bairdii) to strange males of the same species resulted in implantation failure in many cases.

The present experiment examines the relationship between success of implantation and the degree of strangeness of the animal being used as a blocking agent. The technique used to investigate the strangeness factor was to expose inseminated females to animals of three taxa that differ in degree of genetic similarity to the stud male and the inseminated female. Inseminated bairdii females were exposed to strange males or females of one of the following taxa: $P$. m. bairdii, $P$. m. gracilis (an inter-fertile subspecies), or C57BL/10J house mice (members of a different family of rodents).

\section{MATERIALS AND METHODS}

Deermice were raised in the Bar Harbor colony from a stock that has been maintained in the laboratory for 10 years. The females were segregated at

* Department of Zoology, Kansas State University, Manhattan, Kansas, U.S.A. 
weaning (21 to 28 days of age) and housed four per cage until 65 to 75 days of age at which time they were mated in individual cages $(6 \times 12 \times 6$ in. stainless steel). They were, therefore, nulliparous at the beginning of the experiment and, at the time of exposure to strange animals, had had no post-weaning contact with any animals other than females of the same subspecies and their particular stud male. All stud males were 6- to 12-months-old animals of proven fertility. Vaginal smears were examined twice daily after pairing in order to obtain evidence of insemination (inseminations of colony-raised bairdii may occur during the day or night and are only rarely characterized by vaginal plug formation).

After evidence of insemination was obtained, stud males were removed and each female was exposed to one of seven experimental situations: (1) control (female remained in isolation); or (2 to 7) one of six types of strange animals was placed in the inseminated female's home cage for $24 \mathrm{hr}$ beginning on the morning after the day when spermatozoa were detected. These six types of strange animals were male or female bairdii, gracilis or C57BL/10J mice. All exposures were to single, adult, strange animals. After removal of the strange animal, all females remained isolated and undisturbed in their home cages until they were killed on Day 7 post-insemination. The 472 females involved in this experiment were all weaned and used within a 5-month period. The original design included an ordered disposition of animals into the seven treatments until a sample size of forty inseminated females per treatment had been obtained (i.e. every seventh female was delegated to the same treatment). After this original design was complete, sample size was increased in four of the seven treatments in a more or less random manner.

The primary index used to measure the effect of the experimental treatment was presence or absence of embryos on Day 7 post-insemination. In addition, vaginal smears were taken just before the females were killed and non-pregnant mice were categorized as (1) in a stage of vaginal cycling between proestrus and metoestrus or (2) in some other, less easily interpretable, stage of the vaginal cycle or possibly pseudopregnant. The duration of the period from proestrus through metoestrus in bairdii is approximately 3 days (Clark, 1936).

Matings and exposure to strange animals took place in a $12 \times 12 \mathrm{ft}$ room with a fresh air exchange rate of ten times per hour. Females, once mated, were not transferred from one cage to another or from room to room, procedures which stimulate production of ACTH in laboratory mice (Smelik, 1963) and may affect implantation success in deermice (Eleftheriou et al., 1962). Strange animals and stud males were left in the experimental room only as long as necessary and, at all times during the experiment, a one hundred animal limit was maintained in the room.

\section{RESULTS}

A 24-hr exposure to bairdii or $\mathrm{C} 57 \mathrm{BL} / 10 \mathrm{~J}$ males or to either sex of $P . m$. gracilis caused significant reductions in the number of pregnancies when compared to the 81/133 (61\%) pregnancies in the control group (Table 1). Only the presence of bairdii or $\mathrm{C} 57 \mathrm{BL} / 10 \mathrm{~J}$ females failed to reduce the prevalence of pregnancy 
significantly when compared to controls. The significance levels associated with the relative efficiencies of the various types of animals as blocking agents are given in Table 2 . All comparisons were tested by $x^{2}$. In general, the presence of strange bairdii males was very effective in preventing pregnancy while bairdii females were relatively ineffective; both sexes of gracilis caused reductions in the

\section{TABLE 1}

INSEMINATED FEMALES $(P . m$. bairdii) EXPOSED TO STRANGE ANIMALS OR KEPT IN ISOLATION (CONTROLS). CONDITION AT AUTOPSY

\begin{tabular}{|c|c|c|c|c|}
\hline \multirow{3}{*}{ Exposed to: } & \multirow{3}{*}{ No. females } & \multicolumn{3}{|c|}{ Percentage which were: } \\
\hline & & \multirow{2}{*}{ Pregnant } & \multicolumn{2}{|c|}{$\begin{array}{c}\text { Not pregnant; resumption } \\
\text { of oestrous cycle }\end{array}$} \\
\hline & & & Definite & Doubtful \\
\hline $\begin{array}{l}\text { Control* } \\
\text { o bairdii } \\
\text { o bairdii } \\
\text { ot gracilis } \\
\text { o gracilis } \\
\text { o }{ }^{\circ} \text { C57BL/10J } \\
\text { o C57BL/10J }\end{array}$ & $\begin{array}{r}133 \\
90 \\
64 \\
40 \\
40 \\
65 \\
40\end{array}$ & $\begin{array}{l}61 \\
26 \\
52 \\
25 \\
35 \\
42 \\
45\end{array}$ & $\begin{array}{l}25 \\
62 \\
31 \\
55 \\
48 \\
44 \\
40\end{array}$ & $\begin{array}{l}14 \\
12 \\
17 \\
20 \\
17 \\
14 \\
15\end{array}$ \\
\hline
\end{tabular}

* Females remained isolated in home cages for 7 days.

pregnancy rate by a magnitude that was not significantly different from that caused by bairdii males; and, finally, both sexes of C57BL/10J mice were significantly less effective than bairdii males but only the presence of C57BL/10J males was significantly more effective than no exposure at all.

Vaginal smears taken on Day 7 post-insemination revealed that an average

TABLE 2

PROBABILITY LEVELS ASSOCIATED WITH DIFFERENCES IN PERGENTAGE OF ANIMALS PREGNANT AT AUTOPSY (SEE TABLE 1)

\begin{tabular}{|c|c|c|c|c|c|c|c|}
\hline & Control & bairdii $\sigma^{*}$ & bairdii 우 & gracilis $\delta^{\star}$ & gracilis $q$ & $\begin{array}{l}C 57 B L / \\
10 \mathcal{J} \text { ơ }\end{array}$ & $\begin{array}{c}C 57 B L \\
10 \mathcal{J} \text { }\end{array}$ \\
\hline 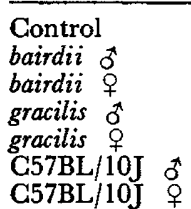 & $\begin{array}{l}<\overline{0.001} \\
\text { N.S. } \\
<0.001 \\
<0.01 \\
<0.01 \\
\text { N.S. }\end{array}$ & $\begin{array}{l}-\overline{0.001} \\
\text { N.S. } \\
\text { N.S. } \\
<0.05 \\
<0.05\end{array}$ & $\begin{array}{c}<\overline{0.01} \\
\text { N.S. } \\
\text { N.S. } \\
\text { N.S. }\end{array}$ & $\begin{array}{l}\overline{\text { N.S. }} \\
\text { N.S. } \\
\text { N.S. }\end{array}$ & $\begin{array}{l}\overline{\text { N.S. }} \\
\text { N.S. }\end{array}$ & $\overline{\text { N.S. }}$ & - \\
\hline
\end{tabular}

of $16 \%$ of the females in this experiment were either pseudopregnant or were in some not easily interpretable stage of the vaginal cycle. There were no apparent differences between the various treatments with respect to the number of females in this category (Table 1 ). The mean number of foetuses per pregnant female ranged from 5.0 to 6.3 among the various treatments, with no significant differences. 


\section{DISCUSSION}

A primary objective of this experiment was to examine Bruce's (1960) conclusion that the effect of a strange male on implantation is greater if the strange male and the stud male are of different strains. The present results relate to a much broader spectrum of genetic difference, and indicate that increasing genetic difference between the stud and test males was not accompanied by an increasing proportion of implantation failures. This work, and that of Bruce (1960) are not directly comparable, since inseminated deermice were used in the present work while Bruce used house mice.

The use of such a broad spectrum of genetic difference probably led to a confusion of mechanisms. The mechanism operating to effect implantation failures in bairdii exposed to strange male bairdii is probably the same as described for house mice by Parkes \& Bruce (1961). Anosmic deermice have not been used in investigating the strange male pregnancy block in bairdii but the available information shows that the phenomenon is quite similar in the two species. As shown in this or in a previous study (Bronson \& Eleftheriou, 1963), stud male or female bairdii are ineffective in producing implantation failures in bairdii, and, as in the house mouse, the block in bairdii is apparently also characterized by a return to oestrus within 7 days. The vaginal smears obtained at autopsy during the present experiment, even though subject to a bias in the sense that only females in proestrus through early metoestrus (a 3-day period) were categorized as cycling, tend to confirm that the block operates on both pregnancy and pseudopregnancy (Table 1 ). In addition, Bronson \& Eleftheriou showed no relationship between implantation success and the number of strange males to which a female was simultaneously exposed. This seems to suggest that 'social stress' as defined by pituitary-adrenal-gonadal responses to crowding (Christian, 1960 ), is probably not a factor in the intra-specific strange male effect in bairdii.

The effect shown for intra-specific exposure in bairdii is therefore probably the same as that described for the house mouse by Parkes \& Bruce (1961), but in inter-specific exposure there was only a slight tendency for males to be more effective blocking agents than females; this suggests that a somewhat different mechanism was involved in the latter case. Enforced cohabitation with an animal of a different species might prove to be socially stressful, as defined by Christian (1960). If so, it would be expected that such exposure would be accompanied by some degree of implantation failure.

\section{ACKNOWLEDGMENTS}

This investigation was supported in part by Public Health Service Research Grant, M-4481, from the National Institutes of Health, and in part by a grant from the Lalor Foundation, Wilmington, Delaware.

\section{REFERENCES}

Bronson, F. H. \& Eleftheriou, B. E. (1963) Influence of strange males on implantation in the deermouse. 7. gen. comp. Endocrinol. 3, 515 .

Bruce, H. M. (1959) An exteroceptive block to pregnancy in the mouse. Nature, Lond. 184, 105. 
BRUCE, H. M. (1960) A block to pregnancy in mice caused by the proximity of strange males. 7 . Reprod. Fertil. 1, 96.

Christian, J. J. (1960) Endocrine adaptive mechanism and the physiologic regulation of population growth. Nav. Med. Res. Inst. Lect. Rev. Series No. 60-2, 49.

ClaARK, F. H. (1936). The estrous cycle of the deermouse, Peromyscus maniculatus. Contrib. Lab. Vert. Genetics, Univ. Mich. 1, 1.

Eleftheriov, B. E., Bronson, F. H. \& Zarrow, M. X. (1962) Interaction of olfactory and other environmental stimuli on implantation in the deermouse. Science, 137, 764.

Parkes, A. S. \& BRUCE, H. M. (1961) Olfactory stimuli in mammalian reproduction. Science, 134, 1049.

SmeLIK, P. G. (1963) Relation between blood level corticoids and their inhibiting effect on the hypophyseal stress response. Proc. Soc. exp. Biol., N.Y. 113, 616. 